\title{
A BASE FOR SIMULATING INFORMATION DISTRIBUTION
}

\author{
Egonsdotter, G., Palmius, J. \\ Department of Information Technology and Media, \\ Mid Sweden University, S-83125 Östersund, Sweden. \\ Gunilla.Egonsdotter@itk.mh.se,Joel.Palmius@itk.mh.se
}

\section{INTRODUCTION}

A common problem with implementation of new communications hardware is that it is difficult to predict their effects on the information flow in an organisation. This leads to hardware investments, which are at best based on qualified guesses that they will improve the situation, and at worst based on half-pronounced promises from the local computer salesman. To help this problem it would be desirable to be able to simulate the information flow in an organisation in such a way that the effects of new hardware implementations could be studied. As the information flow in an organisation can be said to be a complex system, a Cellular Automata (CA) approach is appropriate to build such a simulation. CA approaches have been used for several simulations of complex situations before, as an example, models of combat (Dockery, and Woodcock, 1993) and models of traffic flow (Wahle, et al, 1999). In order to create a simulation, behaviour and information flows must be analysed and formalised using a computerparsable notation language.

During early fall -01, the Cellular Automata Based Simulation of Information Distribution project (CASID) was started as a joint effort between Mid Sweden University (MSU) and Swedish National Defence College (SwNDC). The main participants were doctoral students from the centre for Research on Anticipatory Systems (RAS) at MSU, and from the AQUA group at SwNDC. The intent with the project is to construct software with the ability to simulate how information distributes in an organisation.

The whole project spanned over the entire fall -01 , but the first part of the project consisted of charting, analysing and making operational observed information flows in two exercise organisations. In other words, the first part consisted of an exploratory phase with the purpose of deciding whether it was reasonable to think a simulation could be built. This paper describes the preliminary results of this first part. 
The need to be able to study how information distributes through organisations has lately been a topic for some discussion in connection with ROLF 2010 and AQUA at SwNDC (see below for explanations of ROLF and AQUA). It was felt that new solutions for information distribution were implemented even when the knowledge about their effects was incomplete or lacking. When formulating the project plan for CASID it was thought that one way to get a better base for decisions was through analysing information flows, behaviour and communication and build a simulation thereof.

Both the Swedish Defence Research Agency (FOI) and SwNDC have been studying information behaviour, and have even made formalised descriptions of communication (Wikberg and Modéer, 1999; Albinsson, 2000), but have as far as we know not made a computer-implementable description. Thus one major aim with the first exploratory phase of CASID to make an operational implementable description.

The project described in this paper is formally a part of AQUA, which in its turn was started as a complement to (or part of) ROLF 2010. The Mobile Joint Command and Control System 2010 (ROLF 2010) has the purpose to: "test alternative Command and Control (C2) concepts, work forms, decision-making support and C2 organisations adapted to mobile or movable joint C2 systems for the year 2010" (Sundin, and Friman, 2000).

AQUA (which is a name, not an acronym) is a research and development project with the "Visionarium ${ }^{\mathrm{TM}}$ ", a specially designed room with technical infrastructure for supporting dialogue and decision-making, as its main product (see as an example Artman and Persson, 2000 for description). AQUA has over time developed into an umbrella covering several sub-projects concerning specific issues within the science of Command and Control. One of the planned applications of the results of the CASID project is to be able to study the effects of different configurations of information infrastructure, as an example the implementation of a Visionarium ${ }^{\mathrm{TM}}$.

\section{THE CASE}

SwNDC annually arranges exercises in strategic command as a part of the Programme for Advanced Command Studies. In these exercises, headquarters of command are formed in each of the two groups "battling" each other. The exercise tries to represent a crisis during a wartime situation. The staffs are modelled according to current North Atlantic Treaty (NATO) standards, something that makes analysing the organisation an easier task. This since the above type of organisation has clearly defined goals, clearly defined resources and is strictly hierarchical. To give a comprehensible description of this organisation here would require far too much space. However, a short summary could be as follows:

As said the staffs are organised strictly hierarchical. During the exercises there are operational and tactical command levels. The operational level is responsible for defining the long-term goals, while the tactical level implements the short-term decisions to reach this goal. Information is gathered "on the floor" and where it is sent upwards in the organisation for aggregation and analysis. 
The exercises try implement the organisation during a situation of crisis, such as during a war, but in a somewhat smaller scale. As an example, sometimes a few persons will represent a whole staff.

The people participating in the exercise are a very homogeneous group. They have the same type of education, the same military language and they have good knowledge of the said hierarchical organisation. Thus they can easily understand and communicate with each other, something which might be different during a real situation.

The staffs communicate internally via an information system consisting of a combination of IT tools (email, phones...), meetings and manual routines (messengers, bulletin boards...). One important part of the exercises is to use and test new methods and tools for staff meetings.

\section{THEORY AND WORLD VIEW}

During the last decades, several attempts have been made to simulate human behaviour, and many of these with a specific Artificial Intelligence approach (Vickery and Vickery, 1987). While trying to simulate behaviour and strategies for finding information it has, however, not been the intention of this project to claim that it will implement AI in the traditional sense. The focus has rather been on the information distribution per se, within which the human information-moving behaviours claim a significant role.

It should be noted that when the term "information system" is used in this paper, the humans using the physical infrastructure are considered part of that system. The authors believe that only concentrating on the technical infrastructure of an information system is too limited, since significant parts of the information distribution in an organisation takes places during unplanned encounters in corridors and coffee rooms.

One of the fundamental background theories used in the project is Shannon's Information Theory. It was decided that the traditional model with transmitter, channel and receiver would well describe what the project was trying to simulate. The participants of the project are well aware that it is virtually impossible to handle all the problems of semantics, technology and efficiency described within Information Theory. The military communications are, however, strictly formal, explicit and redundant, properties which might somewhat balance these problems (Fiske, 1997).

Another fundamental theory, or rather technology, which is the base for the whole project, is Cellular Automata (CA). The choice of CA was made since it had previously been applied successfully in battle simulations (Dockery and Woodcock, 1993).

The use of CA necessarily limits the possible variation in worldview when analysing the case situation. First, it is inherent in the technology that systems are described as being very mechanical. Secondly, it is assumed that everything that should be described can be analysed down to explicits without losing anything important on the way: Synergy and relational effects are described as properties of the "cells" rather than modelled separately. Thus, as an example, a group is never described per se. Instead, the individual behaviour when being in the presence of other automatons is modelled. 
While this "all contained in the individual" approach might be discussed in relation to its relevance for descriptions of human behaviour, it is thought in the project that it will be a practical approach to construct a good representation of the said behaviour. It might not be entirely exact, but it could paint a usable picture.

\section{METHOD}

\section{Scope}

Falling outside the scope of the project (and therefore outside this paper), is the actual content of information. To model the significance and consequences of information content would prove far too complex to be possible to handle. Therefore, all material has been studied with the intention, as far as possible, to exclude all information content. The authors realise that this delimitation is a drastic reduction of the situation.

Another aspect is the question about how general the results can be said to be. As mentioned, the modelled situation is a military organisation in crisis (in this case a war situation). The authors cannot, because of this, claim that the results are representative for "normal" organisations.

\section{Methodological steps}

The first step in the project was to do an inventory of existing material about the behaviour and organisation of the said exercises, and in the practise about what the exercises were built to emulate. As SwNDC has significant amounts of documentation, it was necessary to limit the search somewhat.

While having formulated a project vision, a purpose and a goal during the project planning, the first actual step of the project was to formulate an operative picture in the sense of Löwgren and Stolterman (Löwgren and Stolterman, 1998). In practise this consisted of an exploratory modelling of the different entities identified within the situation. This could be viewed as a kind of exploratory research in the sense of Patton (Patton, 1990).

The information points and the behaviour of the observed individuals in the organisation (this material having been fetched primarily from videotapes of the exercises), were analysed with a base in Shannon's Information Theory.

After having constructed a basic operative picture of the situation, the third step consisted of complementing the material with structured deep interviews of exercise leaders, and back-comparisons with the existing documentation. Further, the results have been continually discussed with a senior representative from SwNDC in order to ensure basic reasonableness.

The results of the back-comparison were fed into a new modelling, which were then compared to the documentation, to form iterative steps in an evolutionary design of the models. 


\section{MAKING AN OPERATIONAL DESCRIPTION}

Based on the initial exploratory modelling of the situation, it was agreed that descriptions of four entities could provide a sufficient basis for simulating an information system. These were the physical structure (walls, doors, areas...), the information points (bulletin boards, phones, computers...), the person automatons (with their roles and behaviour) and the actual information.

\section{Information points}

The first and most obvious part of an information system is the physical infrastructure, the points through which the information spreads. In this study the information points are defined as "physical objects with the ability to receive, store and transmit information packets".

The information points were found to be possible to describe using a few general properties. The most notable of these were "send rate", "receive rate", "storage capacity", "medium" and "area of influence".

The send and receive rates are measured in packets per second and define the speed of information transmission between the point and a person automaton. These rates, as well as many of the other properties, are described as a mean and a standard deviation. After discussions with statisticians at MSU, it was in the project group decided that a randomisation from a normal distribution would better describe the values than if the values were chosen from a square distribution. The randomisation function taking the mean and the standard deviation as parameters, and in which $r_{l}=[0,1]$ and $r_{2}=[0,1]$, is described as:

$$
N f ? ?, ? ? ? ? * ? * \sqrt{? 1^{*} \ln \left(r_{1}\right)} * \cos \left(2 ? * r_{2}\right)
$$

The storage capacity decides how many information packets the point can contain before being full. The medium is which type of information packets the point can handle. As an example, a bulletin board can accept pictures and text, but not sound.

The area of influence is two values: one describing how close an automaton must be to receive an information packet from the point, and one how close it must be to add an information packet to the storage of the point.

\section{The physical structure}

The physical structure describes the "arena" within which the person automatons move and operate. It was observed that a significant part of the information distribution was done in chance encounters within corridors and in the coffee room. Therefore it was decided that the simulation needed to recapture the movements of the individuals, even when they did not explicitly work with information distribution. 
In order to provide a basis for the behaviour schemata (described below), key areas were implemented. These areas represent localities where the individuals within the organisation spend time, such as "lunch room", "personal office", "corridor" and "bathroom".

The description of the arena will (when these descriptions are implemented) be modelled in a special editor. In practise this work will consist of trying to represent a plan sketch of the modelled building.

Within the arena, the information points described above will be placed according to the modelled situation.

\section{Information packets}

The definition of an information package is in this study "a discreet quantity of data". While in the simulation being completely devoid of actual content, they represent "information" in the modelled situation. Therefore the term is "information package" rather than "data package".

The information packages have four main parameters: A serial number, a type, a priority and a class. The serial number is plainly a unique identifier to enable tracing of specific packages. The type is the media through which the information can be spread, at this stage "visual", "text" or "audio". This decides through which information points the package can be spread. The priority is "normal", "medium" or "high", and provides a base for selection when the automatons have several information packages to choose between.

The class is primarily a way of grouping a stream of information packages, in order to provide a base for statistics after the simulation run. The class also decides whether the information package exists when the simulation starts, or if it has to be constructed through an aggregation of other information packages.

\section{Person automatons and their behaviour}

The by far most complex modelling was that of the behaviour of the person automatons. At the time of writing this modelling is only partly finished, and therefore what is offered below is the preliminary results of this modelling.

The person automatons represent the individuals working within the organisation. As a simulation might contain several hundred person-automatons, it was early decided that it would be impossible to describe all the represented automatons individually. Instead, the preliminary modelling was aimed at grouping behavioural patterns into a number of distinct classes. As these groups do not necessarily equate with a formal function within the organisation, the term "behaviour group" was chosen rather than "role" in order to avoid confusion when discussing with personnel at SwNDC. 


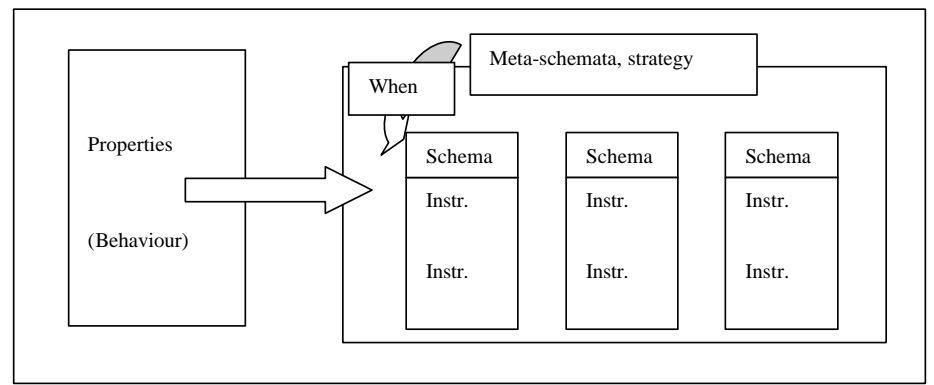

Figure 1: The behaviour of a person automaton consists of schemata and a strategy controlling when the schemata are triggered.

A person automaton consists of several properties and a general behaviour. Most of the properties, and the whole behaviour, are inherited from the definition of the behaviour group to which the automaton belongs.

The behaviour is an aggregate of a number of schemata (such as a schema for "take coffee break"), and a meta-schema controlling the overall strategy of the automaton. The schemata will be triggered through events in the environment ("interact with automaton met in corridor"), according to schedule ("take lunch break", "sleep") and according to the overall strategy ("look for information through email in personal office").

The schemata consist of "instructions" or in other words a low-level code language with atomic functions such as "go to area", "wait" and "interact with point". At the moment of writing, this language is at best at a conceptual stage. Apart from the behaviour, the automatons will have properties such as "position in organisation" and "home area".

\section{XML:ifying the entities}

As a basis for a simulation the models are pointless unless they are possible to implement in code. Therefore, all the modelling were made with the possible ways for implementation as a constant points of reference. Parallel to the conceptual modelling, the project members have worked with describing the results of the models in XML code.

At the moment of writing, preliminary document type definitions (DTD) exist for the physical structure and for the information points. Initial attempts at describing behaviour and schemata have been made.

\section{SUMMARY AND CONCLUSIONS}

The above material describes the preliminary results of the first exploratory phase of the CASID project, a material which will serve as a base for the further work. As 
such, the models and operational descriptions can be seen as somewhat sketchy. However the purpose with the described phase was to collect information and do preliminary exploratory modelling in order to decide whether it could be believed that a simulation of the mentioned kind could be built. With the existing material, the authors of this paper are quite confident that believing so is reasonable.

The further work will be concentrated at polishing the models, and to implement them as Java-based software. Work with formulating DTDs for the description language used in the applications has, as mentioned, already begun. As material of this kind start to mature, it will be made available on the project homepage (Egonsdotter and Palmius, 2001).

The initial attempts at trying to describe information distribution through modelling individual behaviour and modelling the structure the individuals interact with, indicates interesting possibilities. The approach to describe human behaviour as a number of schemata constructed by low-level instructions, and aggregating into an overall behaviour, seems promising at this stage.

In spite of the above operational description being a drastic reduction of human behaviour, it is the belief of the authors that a simulation based on the material can serve as useful tool for studying information distribution, and for being a decision support for implementations of new technological structures.

\section{REFERENCES}

Albinsson, P.A. (2000). Visualisering av loggfiler - ett hjälpmedel för utvärdering av verksamhetsmodeller. FOA, Linköping, Sweden.

Artman, H., and Persson, M. (2000). "Old Practices - new technology: Observation of how established practices meet new technology". In ROLF 2010 the way Ahead and The First Step (C. Sundin and H. Friman, eds.) The Swedish National Defence Collage, Department of Operational Studies and the Centre for Command and Control Science, Stockholm, Sweden.

Dockery, J., and Woodcock, A. (1993). The Military Landscape - Mathematical Models of Combat. Woodhead Publishing Limited, England.

Egonsdotter, G., and Palmius, J. (2001) CASID - Homepage. Available: Http://gathering.itm.mh.se/casid.

Fiske, J. (1997). Kommunikationsteorier: en introduktion. Central tryckeriet AB, Borås, Sweden.

Löwgren, J., and Stolterman, E. (1998). Design av Informationsteknik - Materialet Utan Egenskaper. Studentlitteratur, Lund, Sweden.

Patton, M.Q. (1990). Qualitative Evaluation And Research Methods. SAGE Publications, Inc.,USA

Sundin, C., and Friman, H. (2000). ROLF 2010 the way Ahead and The First Step. The Swedish National Defence Collage, Department of Operational Studies and the Centre for Command and Control Science, Stockholm, Sweden.

Vickery, B.C., and Vickery, A. (1978). Information Science in Theory and Practice. BowkerSaur,

London, England. 
Wahle, J., Neubert, L., Esser, J., and Schreckenberg, M. (1999). "A Cellular Automaton Traffic Flow Model for Online Simulation of Traffic". Parallel Computing, 27: 719-735.

Wikberg, P., and Modeér, B. (1999). Modellering av operativ ledningsenhet - Visuell modellering

som metod för problemanalys och operationalisering av begrepp i komplexa system. FOA, Linköping, Sweden. 